\title{
OFFICE WORKER'S EXPOSURE TO VOLATILE ORGANIC COMPOUNDS WHILE COMMUTING AND WORKING IN TAIPEI CITY
}

\author{
Chang-Chuan Chan and Shou-Hsiang Lin \\ National Taiwan University, College of Public Health, Institute of Occupational Medicine and Industrial \\ Hygiene, No. 1 Jen-Ai Rd, 1st Sec., Taipei, Taiwan \\ and \\ GuOR-Rong Her \\ National Taiwan University, Department of Chemistry, No. 1 Roosevelt Rd, 4th Sec., Taipei, Taiwan
}

(First received 8 October 1992 and in final form 1 October 1993)

\begin{abstract}
This study examined office workers' exposure to volatile organic compounds (VOCs) from two activitics: commuting and working in an office in Taipei, Taiwan in the spring of 1992. About 18 target $\mathrm{C}_{6}-\mathrm{C}_{10}$ hydrocarbons and chlorinated VOCs were collected on Tenax-GC adsorbent tubes, and analysed by a thermal desorption and GC-MS method. We found that similar VOC species were present in commutes and in offices except that chloroform and 1,1,1-trichloroethane were only present in offices. The in-vehicle VOC concentrations in Taipei were about 2-30-times higher than the levels in many western cities. The VOC concentrations in commute varied only with different commuting vehicles. The in-vehicle VOC concentrations were not affected by either time-of-day or route-of-traffic. On the average, the VOC concentration ratio of motorcyclist: private vehicle-driver: bus-rider was about $5: 3: 2$. The round-trip commuting duration ratio of motorcyclist: private vehicle-driver: bus-rider was $1: 1.5: 2$. The VOC concentrations in commute were about 5-11 times higher than in offices. We concluded that motorcyclists had the highest VOC exposures while commuting in Taipei. The comparisons of VOC profiles in various microenvironments indicated that auto exhaust emissions were the main VOC sources in vehicle and in office. In general, office workers' benzene exposures during commuting were greater than at work in Taipei.
\end{abstract}

Key word index: Volatile organic compounds, benzene, chloroform, exposure assessment, commuters.

\section{INTRODUCTION}

The emission of volatile organic compounds (VOCs) from vehicles has been a long-time interest of air pollution researchers because some VOCs are important precursors of photochemical reactions in forming urban smog. More recently, VOC studies also focused on the problem of air toxics, such as benzene. The commuting has been identified as one of most important activities in getting benzene exposure in the U.S. EPA's Total Exposure Assessment Methodology (TEAM) study (Wallace, 1987). More studies were followed to measure the VOC concentrations directly either inside cars, subways, or from cyclists' breathing zones in the U.S. and the U.K. (Chan et al., 1991, 1992; Weisel et al., 1992; Bevan et al., 1991; SCAQMD, 1989). Although these studies succeeded in documenting factors in influencing the commuters' VOC exposures while commuting, they failed in estimating their actual exposures in respective population. The lack of commuting patterns and enough VOC measurements is one of the main reasons for such failure. We, therefore, designed a study to estimate a population's exposure to VOCs while commuting by establishing commuting patterns and by measuring in- vehicle VOC concentrations in Taipei. The entire study included two sub-groups, i.e. office workers and students. Only the results of office workers were presented in this paper. We examined differences in invehicle VOC concentrations among the three most popular commuting tools for office workers in Taipei, i.e. bus, car and motorcycle. We also identified impact of in-vehicle VOC concentrations by some key commuting elements, such as, time of day and route of traffic. Additionally, we measured VOC concentrations in workers' offices in order to compare their VOC exposures during commuting and at work.

\section{METHODS}

\section{Commuting patterns}

A questionnaire survey was conducted to establish the commuting patterns of office workers in downtown Taipei (the Chung-Zen District). We classified all office buildings with more than 50 workers in the district into three categories: private companies, governmental buildings and schools. A total of $\mathbf{3 8 6}$ office workers from two private companies, one governmental office and one school were randomly selected to fill the questionnaire. The information about time of leaving homes/offices, duration of each trip, routes of each trip, and commuting tools was obtained in the questionnaire. 


\section{VOC measurements}

Three major commuting routes toward downtown Taipei identified from the commuting pattern survey were chosen for VOC sampling. One was from the north, another from the east and the third from the south. We assigned one commuter by bus, another by motorcycle and the third by private car on each route. They were all non-smokers. Three private cars were one Ford (1500 cc, 1982), one Yue-Long (1600 cc, 1988), and one Toyota $(1600 \mathrm{cc}, 1989)$. The buses and cars used in this study were using air conditioning with windows closed during the sampling period. Their spceds were about $30-40 \mathrm{~km} \mathrm{~h}^{-1}$. Smoking was not allowed inside air conditioning buses in Taipei. These three participants were matched to start the sampling instruments simultaneously on each sampling. All commuters were wearing personal samplers during the commutes. The mode time that most office workers left homes and offices, identified in the commuting pattern survey, were set to be the start-time of VOC sampling. In order to estimate these office workers' VOC exposure at work, fixed-site samples were collected in the office of three institutions, one private company, one governmental office and one research institute, in downtown Taipei for six consecutive days. Two samples were collected on each site daily for six consecutive days. The VOC field sampling was carried out from 20 to 26 March 1992. The weather condition was generally overcast with an averaging temperature of $22^{\circ} \mathrm{C}$ in the daytime and $20^{\circ} \mathrm{C}$ in the nighttime during these days in Taipei.

\section{Sampling and analytical methods}

Eighteen VOCs, ranging from $\mathrm{C}_{6}$ to $\mathrm{C}_{10}$, were measured in this study. The VOCs measured were 3 aliphatic hydrocarbons, 1 olefinic hydrocarbon, 12 aromatic hydrocarbons, and 2 chlorinated hydrocarbons. The U.S. EPA TO-1 method was modified to collect and analyse these 18 VOCs (Winberry et al., 1988). The sampling system consisted of a stainless steel tube $(178 \mathrm{~mm} \times 5.2 \mathrm{~mm}$ ID) with $0.4 \mathrm{~g}$ Tenax-GC, and a low-flow sampling pump (SKC Inc., Model 222). The sampling rate was adjusted at $50 \mathrm{ml} \mathrm{min}^{-1}$ for commuters and $30 \mathrm{ml} \mathrm{min}^{-1}$ for fixed sites. The sampling duration ranged from 0.5 to $1 \mathrm{~h}$ for commuter measurements, and from 3 to $4 \mathrm{~h}$ for fixed-site measurements. The VOCs were trapped on the Tenax-GC tubes. The analysis of VOCs from the Tenax-GC tubes was performed by a high resolution gas chromatography/mass spectrometry (GC/MS) technique. The major components of the system were a thermal desorption system (Tekmar Inc., Model 5010 GT), a capillary gas chromatographic system $(50 \mathrm{~m} \times 0.2 \mathrm{~mm}$ HP-1 fused silica capillary column), a quadruple mass spectrometer (HP 5971A) and a data processing system (HP G1030A MS ChemStation). The thermal desorber used a two-step desorption program to desorb the sampling tubes using helium as a carrier gas. First, the tubes were thermally desorbed at $200^{\circ} \mathrm{C}$ for $8 \mathrm{~min}$. Second, they were trapped by liquid nitrogen at $-120^{\circ} \mathrm{C}$. Third, they were ballistically heated to $270^{\circ} \mathrm{C}$ again. Finally they were cryogenically focused at $-120^{\circ} \mathrm{C}$ before injection. The initial oven temperature of $\mathrm{GC}$ was set at $40^{\circ} \mathrm{C}$ for $2 \mathrm{~min}$, and ramped first slowly to $120^{\circ} \mathrm{C}$ at the rate of $4^{\circ} \mathrm{C} \mathrm{min}^{-1}$, and held for $3 \mathrm{~min}$, and ramped very quickly to $240 \mathrm{C}$ at the rate of $60 \mathrm{C} \mathrm{min}^{-1}$. The identification of each compound was confirmed by its retention time and mass spectrum. The quantification of target VOCs was accomplished by using the calibration curves of six different concentrations of all target compounds and the internal standard (perfluorotoluene) in each samples.

\section{Quality assurance and quality control}

Three sets of quality control samples were prepared to evaluate the accuracy of the sampling and analytical system for the target VOCs. Each set contained an unspiked sampling tube to serve as a blank sample and a spiked one as a control sample. Most target VOCs had recovery efficiencies greater than $85 \%$ except heptene. Seven pairs of duplicates were collected and analysed to assess the precision of the method. The relative mean deviation of these duplicates was within $10 \%$ for all target VOCs. Three sampling tubes spiked with $10 \mathrm{ng}$ of VOC standards were used to determine the detection limits (LODs) of the system. The LODs of the sampling methods ranged from 0.46 to $0.95 \mu \mathrm{g} \mathrm{m}^{-3}$ for most target VOCs based on the average sampling volume of $5 \ell$.

\section{RESULTS}

We found that bus, motorcycie and car were the three most widely used commuting tools among the eight commuting modes for the commuters in Taipei in our questionnaire survey (Table 1). In total there were about $84.5 \%$ of all surveyed commuters who used these three tools for their daily commutes. The rest were commuting either by walking, train, taxi, bike, or shuttle bus. Based on these findings, we decided to measure VOC concentrations only in bus, car and motorcycle. Among these three types of commuters,

Table 1. Summary of office workers' commuting patterns in Taipei, $1992(n=386)$

\begin{tabular}{|c|c|c|c|c|c|c|c|c|}
\hline & Walk & Bus & Bike & $\begin{array}{r}\text { Motor- } \\
\text { cycle }\end{array}$ & Shuttle bus & Train & Taxi & Car \\
\hline Number of people & 25 & 152 & 7 & 98 & 4 & 17 & 8 & 73 \\
\hline Percentage of total & 6.5 & 39.6 & 1.8 & 25.5 & 1.0 & 4.4 & 2.1 & 19.0 \\
\hline Age & $\begin{array}{c}34^{*} \\
(22-63)+\end{array}$ & $\begin{array}{c}32 \\
(15-64)\end{array}$ & $\begin{array}{c}33 \\
(21-58)\end{array}$ & $\begin{array}{c}29 \\
(18-53)\end{array}$ & $\begin{array}{c}30 \\
(20-36)\end{array}$ & $\begin{array}{c}31 \\
(18-48)\end{array}$ & $\begin{array}{c}37 \\
(22-51)\end{array}$ & $\begin{array}{c}38 \\
(24-61)\end{array}$ \\
\hline $\begin{array}{l}\text { Home-to-office } \\
\text { (min) }\end{array}$ & $\begin{array}{c}18 \\
(1-40)\end{array}$ & $\begin{array}{c}50 \\
(15-107)\end{array}$ & $\begin{array}{c}21 \\
(9-40)\end{array}$ & $\begin{array}{c}32 \\
(10-100)\end{array}$ & $\begin{array}{c}55 \\
(20-100)\end{array}$ & $\begin{array}{c}57 \\
(20-100)\end{array}$ & $\begin{array}{c}49 \\
(25-120)\end{array}$ & $\begin{array}{c}42 \\
(8-100)\end{array}$ \\
\hline \multicolumn{9}{|c|}{$(100-100)(20-100)(20-100) \quad(20-120)$} \\
\hline $\begin{array}{l}\text { Office-to-home } \\
\text { (min) }\end{array}$ & $\begin{array}{c}17 \\
(1-40)\end{array}$ & $\begin{array}{c}56 \\
(15-121)\end{array}$ & $\begin{array}{c}22 \\
(9-40)\end{array}$ & $\begin{array}{c}35 \\
(5-95)\end{array}$ & $\begin{array}{c}44 \\
(15-85)\end{array}$ & $\begin{array}{c}65 \\
(30-130)\end{array}$ & $\begin{array}{c}59 \\
(30-90)\end{array}$ & $\stackrel{48}{(10-105)}$ \\
\hline \multicolumn{9}{|l|}{ Distance } \\
\hline $\begin{array}{l}\text { Home-to-office } \\
\quad(\mathrm{km})\end{array}$ & $\begin{array}{c}1.5 \\
(0.5-7)\end{array}$ & $\begin{array}{c}8 \\
(0.8-45)\end{array}$ & $\begin{array}{c}5.3 \\
(1.2-10)\end{array}$ & $\begin{array}{c}10 \\
(1-45)\end{array}$ & $\begin{array}{c}5 \\
(3-10)\end{array}$ & $\begin{array}{c}25 \\
(10-40)\end{array}$ & $\begin{array}{c}12.5 \\
(4-18)\end{array}$ & $\begin{array}{c}10 \\
(1.5-40)\end{array}$ \\
\hline
\end{tabular}

- Median value.

† Values in parantheses are range. 


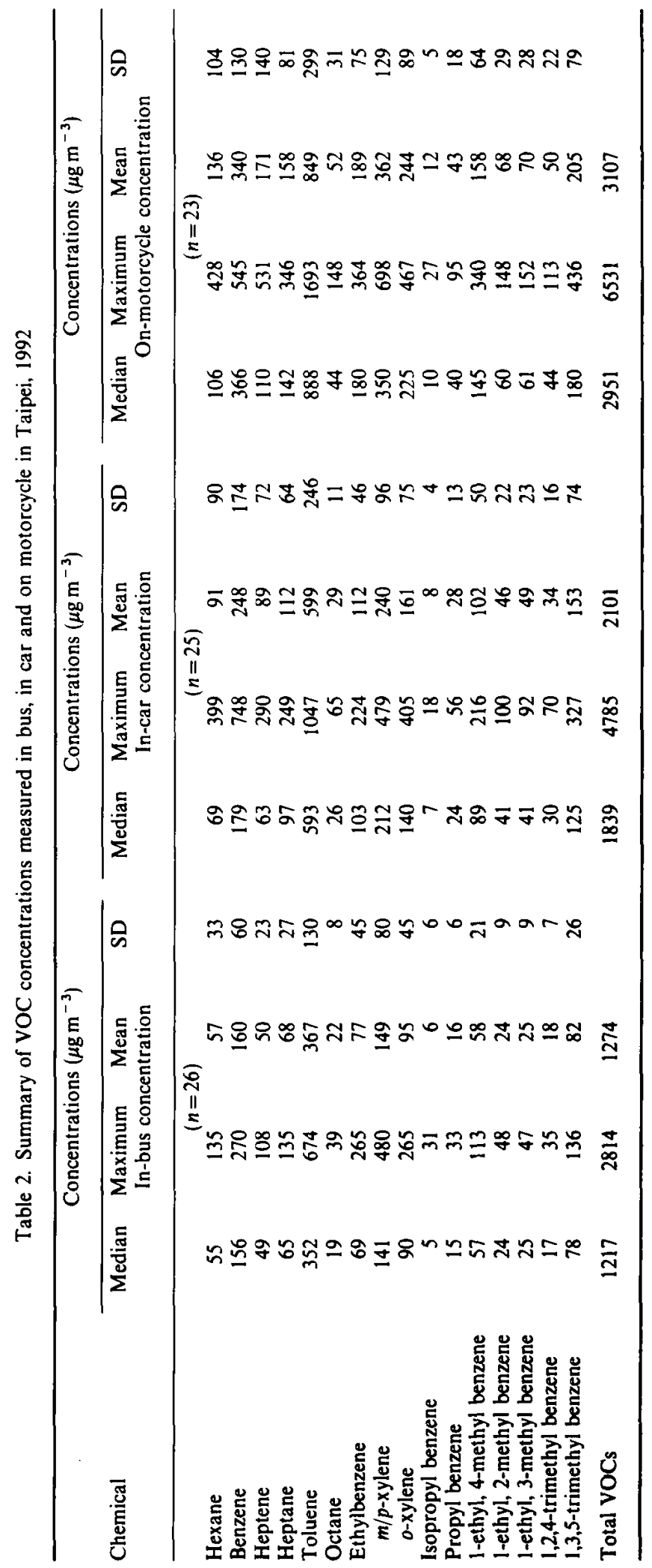


private-car commuters were the eldest (38-years-old), while the motorcyclists were the youngest (29-yearsold). The bus commuters had the longest commuting duration, while the motorcyclists had the shortest. The median round-trip duration of daily commute was about $1 \mathrm{~h}$ for using motorcycles, $1.5 \mathrm{~h}$ for driving private cars, and $2 \mathrm{~h}$ for taking buses. The bus commuters, however, had a shorter distance of commute than the private-car drivers and motorcyclists. The median one-trip distance of commute was about $8 \mathrm{~km}$ for bus commuters, $10 \mathrm{~km}$ for motorcyclists, and $10 \mathrm{~km}$ for private-car commuters. We also found that most office workers started their morning commutes at 7:30 a.m. and their afternoon at 5:30 p.m.

We found substantial difference in VOC concentrations among these three commuting tools $(p<0.01)$ (Table 2). The concentrations of 16 measured VOCs averaged at $3.1 \mathrm{mg} \mathrm{m}^{-3}$ on motorcycle, $2.1 \mathrm{mg} \mathrm{m}^{-3}$ in private car, and $1.3 \mathrm{mg} \mathrm{m}^{-3}$ in bus in Taipei during commutes. The in-vehicle VOC concentration ratios of motorcycle/car/bus were about $5: 3: 2$. The higher on-motorcycle VOC concentrations can be due to motorcyclists' proximity to tail-pipe emissions on the roads. Toluene, benzene, and $m-/ p$-xylene were three most abundant species among the aromatic VOCs. The mean concentrations of benzene were $160 \mu \mathrm{g} \mathrm{m}^{-3}$ in bus, $248 \mu \mathrm{g} \mathrm{m}^{-3}$ in car, and $372 \mu \mathrm{g} \mathrm{m}^{-3}$ on motorcycle, respectively. The in-vehicle benzene concentrations in Taipei were higher than the levels measured in several western cities (Table 3). The commuters were exposed to about $31-50 \mu \mathrm{g} \mathrm{m}^{-3}$ in Los Angeles (SCAQMD, 1989), $12 \mu \mathrm{g} \mathrm{m}^{-3}$ in Raleigh (Chan et al., 1991), $17 \mu \mathrm{g} \mathrm{m}^{-3}$ in Boston (Chan et al., 1992), $9-26 \mu \mathrm{g} \mathrm{m}^{-3}$ in New Jersey (Weisel et al., 1992), and $37-82 \mu \mathrm{g} \mathrm{m}^{-3}$ in London (Bevan et al., 1991). On average, in-vehicle benzene concentrations in Taipei were about 2-30-times higher than those in some big cities in developed countries like Los Angeles, Boston, and Raleigh. Furthermore, benzene concentrations experienced by motorcyclists in Taipei were about 7-40-times higher than cyclists in London and Boston. Besides that, we found that a higher proportion of alkylated benzene compounds in these VOC measurements, such as, propyl benzenes, and ethyl-methyl benzenes. This phenomenon could be attributable to a relatively high proportion of aromatic components, including the benzene content, in the gasoline products and the low proportion of emission controlled cars and motorcycles in Taiwan. In 1991, the aromatic components in gasoline averaged at $35 \%$ in Taiwan according to the Chinese Petroleum Company, a state-run monopoly. In addition, the catalyst-equipped cars were minimal among the cars and motorcycles in Taiwan since only new cars after 1 July 1990, were required to meet emission standards which were equivalent to the 1983 U.S. standards. In contrast to this, the aromatic component in gasoline averaged at $29.5 \%$ and the rate of the catalyst-equipped vehicles were about $88 \%$ in the U.S. in 1988 .

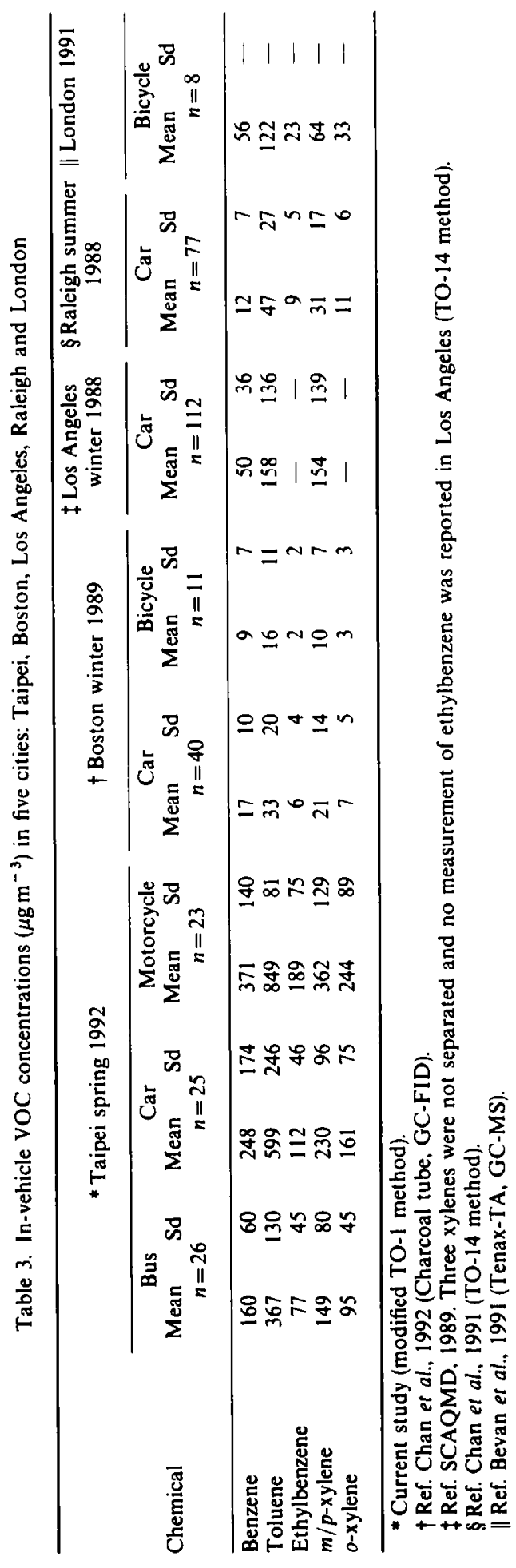


The VOC concentrations on the roadways of Taipei showed no significant difference between morning and afternoon rush hours $(p>0.01)$ (Fig. 1). This can be explained by the fact that temperature changes between daytime and nighttime in a subtropical city like Taipei are small, which makes the variation of temperature-dependent auto-exhausts become minimal. There were also no significant difference in VOC concentrations among three commuting routes except that the in-car VOC concentrations on the eastbound commuting route were higher than other two routes ( $p>0.01)$ (Fig. 2). Further investigation showed that the air conditioning of the car used in the east-bound route was broken and the driver opened the windows during the sampling period. It is not unexpected that there were similar VOC commuter exposure on these three routes because the traffic volume and traffic jams along these three main traffic routes during rush hours were also very similar in Taipei. The temporal and spatial consistency in commuter exposure to VOCs, therefore, simplified our assumptions in applying the measured data to estimating exposures in the general population.

The VOC measurements in offices showed slightly different VOC species from the VOC measurements on roads (Table 4). There were significant amount

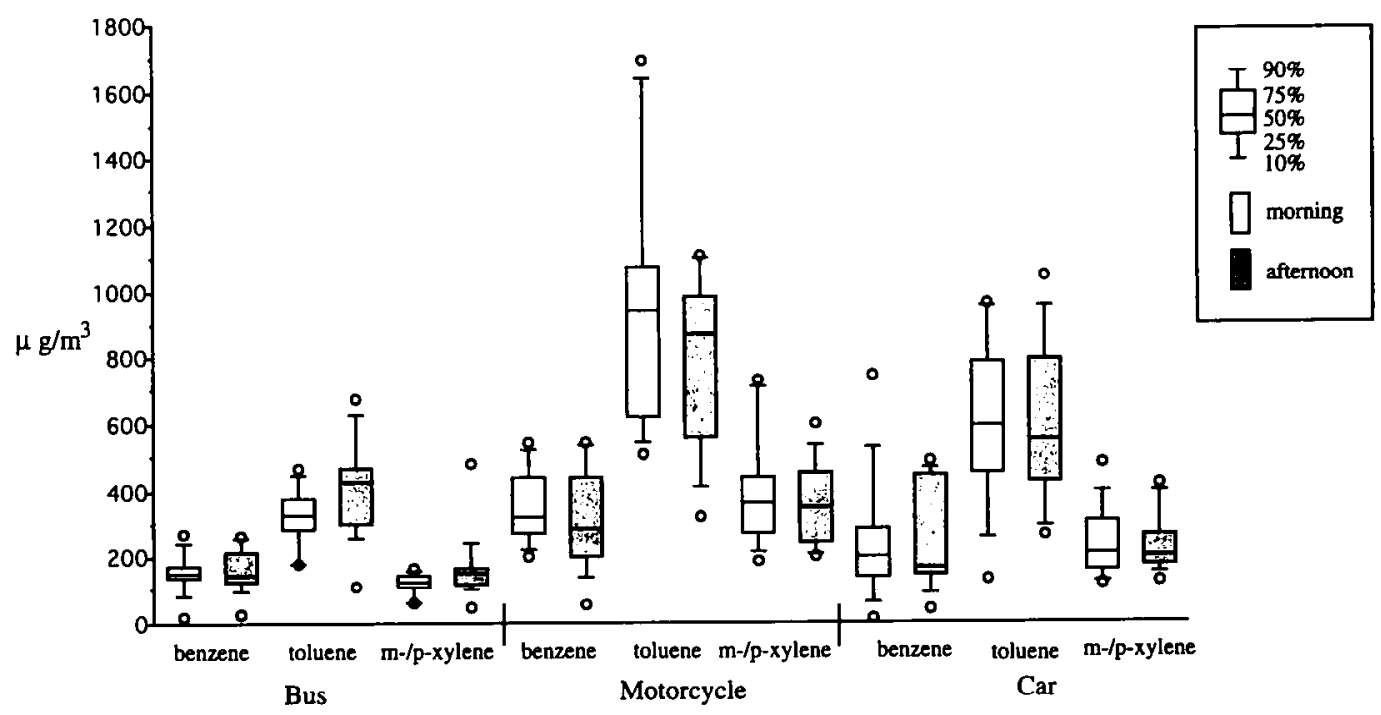

Fig. 1. Comparison of in-vehicle concentrations between morning and afternoon rush hours.

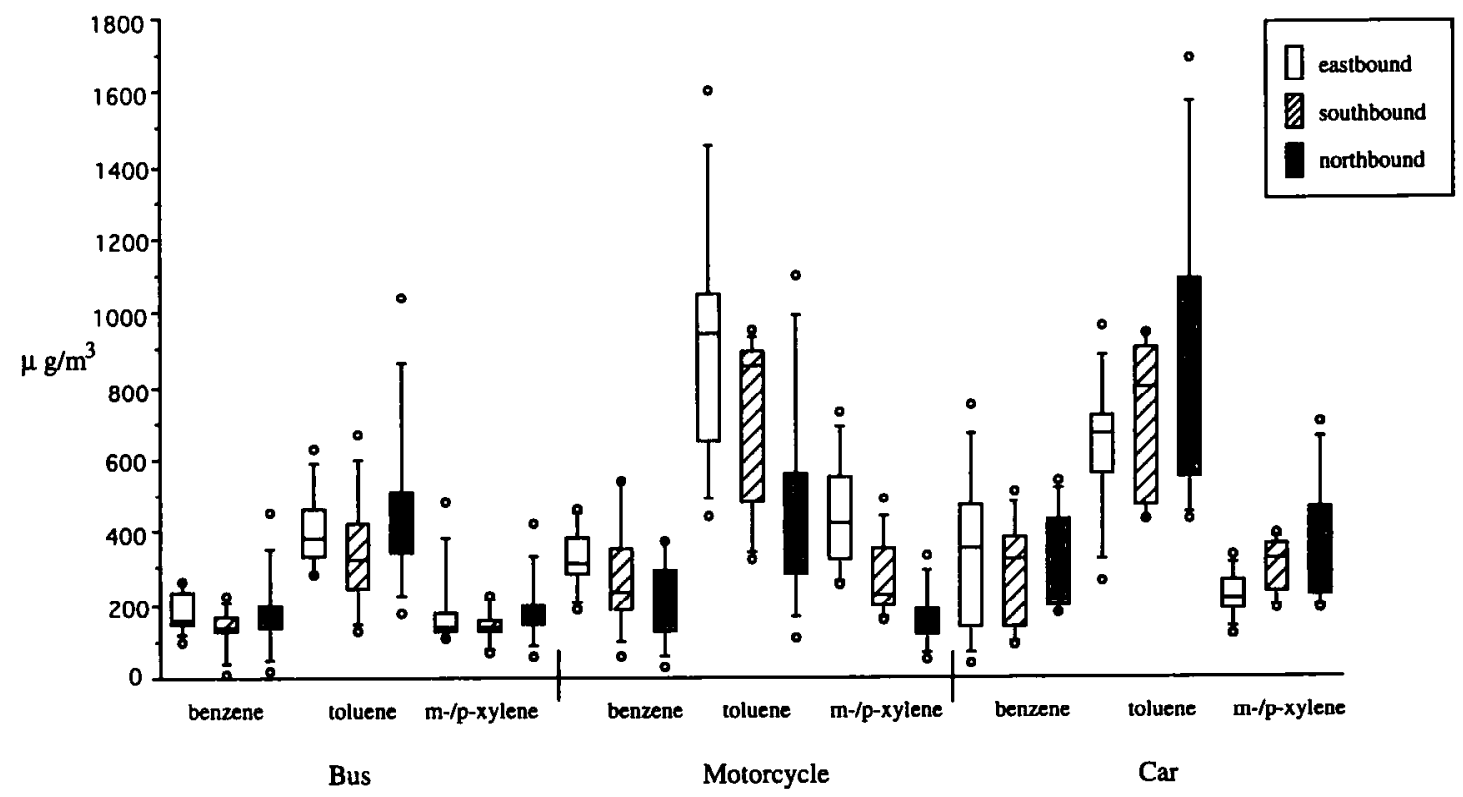

Fig. 2. Comparison of in-vehicle VOC concentrations among three traftic routes. 


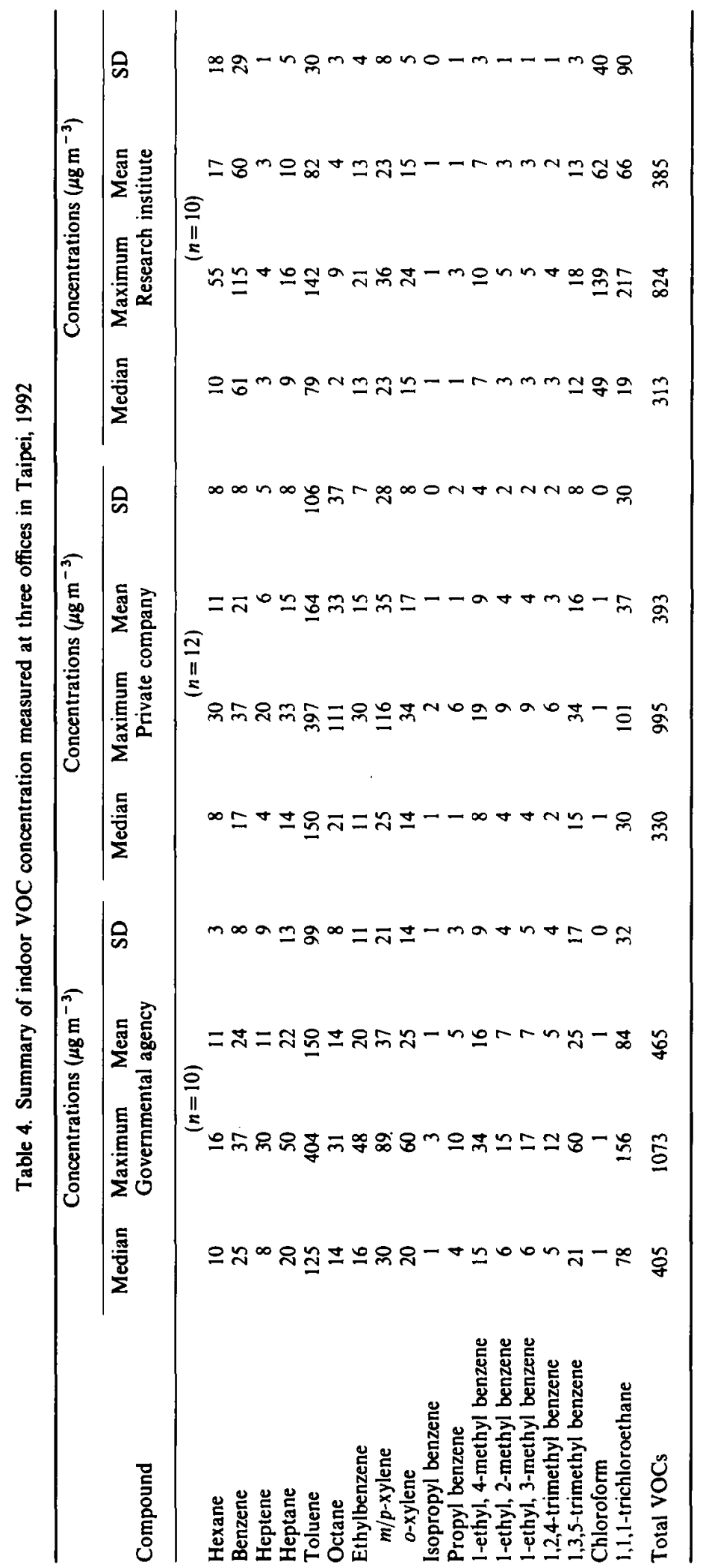


of 1,1,1-trichloroethane concentrations in all three offices. Since liquid paper was widely used by workers in these three offices, we believed that 1,1,1-trichloroethane-containing liquid paper was the main emission source. We also found relatively high chloroform concentrations in the office of the research institution. The mean chloroform concentration in this office was $62 \mu \mathrm{g} \mathrm{m}^{-3}$ over five sampling days. Since this office is very close to a chemical laboratory, we think chloroform most likely comes from the nearby laboratory. Among the 16 overlapped VOCs, the VOC concentrations in office were significantly lower than those on the road $(p<0.01)$. Taking benzene as an example, in-office concentrations were about $1 / 5$ of in-bus concentrations, $1 / 8$ of in-car concentrations. and $1 / 11$ of on-motorcycle concentrations.

We used the results of correlation among VOCs as a way to identify common emission sources in different microenvironments. By correlating measurements of benzene with measurements of the other 15 nonchlorinated VOCs either in commutes or in offices, we found that benzene measurements were moderately correlated with measurements of other aromatics. The correlation coefficients between benzene and other aromatics ranged from 0.51 to 0.74 . This indicated that benzene detected in offices as well as in vehicles were possibly associated with the same emission sources, i.e. automobile emissions. Additionally, we compared VOC profiles to identify specific VOC sources in different microenvironments. The benzenebased VOC profiles were calculated by devising concentrations of toluene, ethylbenzene, $m-/ p$-xylenes, and $o$-xylene by benzene concentrations, respectively (Fig. 3). Profile comparisons indicated that measurements of these five compounds in bus and on motorcycle were very similar. Since the auto-exhaust profile was not available in Taiwan, we compared our measurements with the auto-exhaust profile in the
U.S. (Edgerton et al., 1989), and found a similarity among them. The alkylated-benzenes/benzene profiles in private cars were, however, different from the profiles in the other two vehicles. There were possibly sources of VOC emissions from car interiors. Since there were no measurements of emissions from upholstery and plastic in three private cars, we are not able to quantify the contribution of these sources to in-car VOC profiles. Another particular feature of our VOC profiles was that there were high toluene/benzene ratios in governmental and private companies' offices. Since toluene was a universal solvent for many products, it was possibly emitted from some products and furnishings used in these offices. We also found that alkylated-benzenes/benzene ratios were lower indoors than on the road. This was possibly due to alkylatedbenzene's faster transformation than benzene while dispersion since photochemical reactivity of alkylated-benzenes was higher than benzene.

We combined information about commuting patterns with measured in-vehicle VOC concentrations to calculate commuters' expected exposures to VOCs while commuting in Taipei. The expected mean/ median exposures were calculated by multiplying mean/median values of round-trip commuting duration (in minutes) with measured VOC concentrations (in $\mathrm{mg} \mathrm{m}^{-3}$ ) (Table 5). For round-trip exposures, motorcyclists had the greatest exposures, while bus-rides had the smallest exposures. The median exposures of 16 VOCs were $124 \mathrm{mg} \mathrm{m}^{-3}$-min for busriders, $157 \mathrm{mg} \mathrm{m}^{-3}$-min for private vehicle-drivers, $181 \mathrm{mg} \mathrm{m}^{-3}$-min for motorcyclists during commutes. The median benzene exposures were $16 \mathrm{mg} \mathrm{m}^{-3}$-min for bus-riders, $15 \mathrm{mg} \mathrm{m}^{-3}$-min for private vehicledrivers, $22 \mathrm{mg} \mathrm{m}^{-3}$-min for motorcyclists during commutes. In contrast, the median benzene exposures at work were $12 \mathrm{mg} \mathrm{m}^{-3}$-min at the governmental agency, $29 \mathrm{mg} \mathrm{m}^{-3}$ - $\mathrm{min}$ at the research institute, and

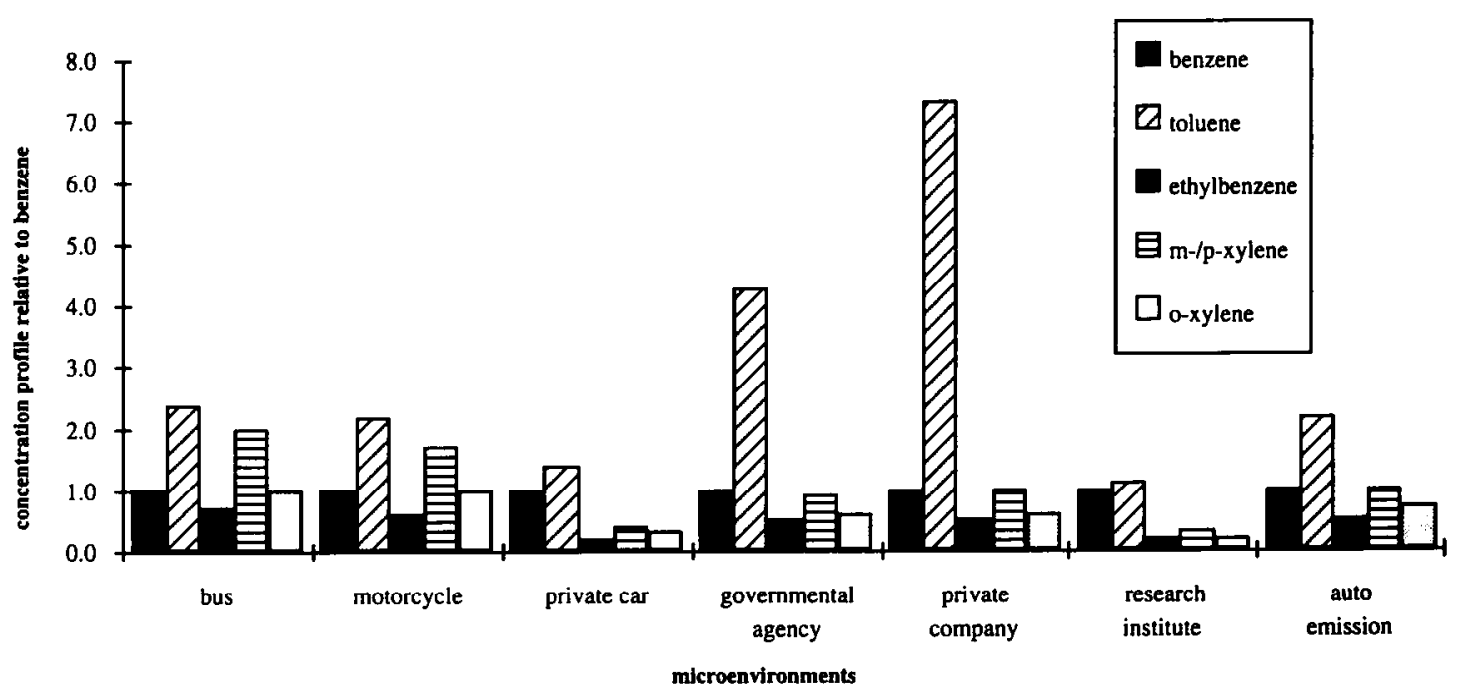

Fig. 3. Comparison of median VOC concentration profiles in six microenvironments in Taipei with a U.S. auto emission profile. 


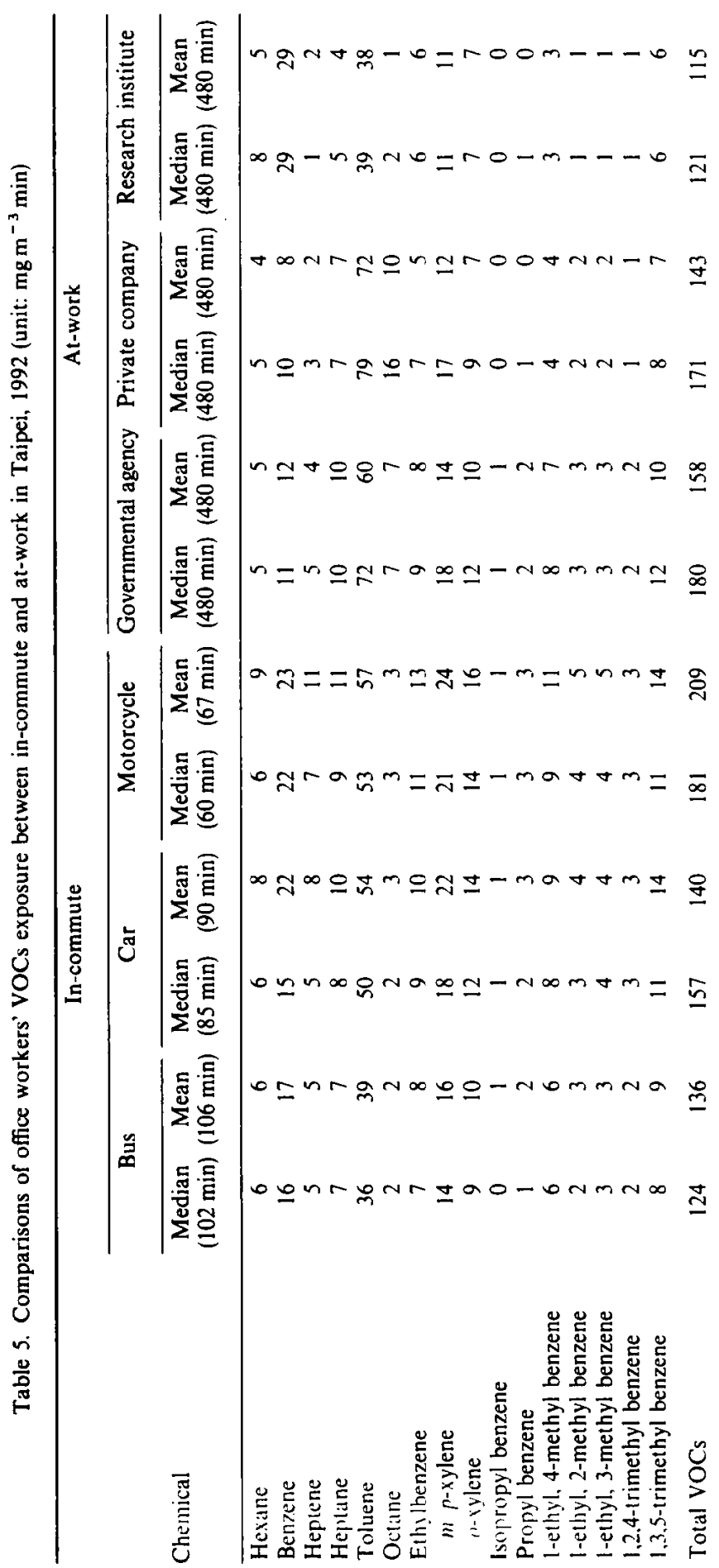


$10 \mathrm{mg} \mathrm{m}^{-3}$-min at the private company assuming an 8-h working duration daily. Although the workers usually spent their time $7-8 \mathrm{~h}$ longer at work than in commute, their benzene exposures in commute were generally equivalent to their exposures at work. Since the commuting and working exposures are both relatively high, we believe that programs of reducing workers' benzene exposures in commute as well as at work are warranted in Taipei.

\section{- CONCLUSION}

We identified that both in-vehicle and in-office benzene concentrations in Taipei were extraordinarily higher than many other cities in developed countries. In addition, the in-vehicle VOC concentrations while commuting varied only with type of vehicles, but not with route of commute nor time of day for commuting in Taipei. Most of the in-vehicle and indoor nonchlorinated VOCs, such as, benzene, toluene, and xylenes were mainly from emissions of mobile sources. However, toluene, may be contributed by some indoor emission sources in certain offices. In contrast, chlorinated VOCs, such as, chloroform and 1,1,1trichloroethane were mainly from indoor sources. We recommend that a series of pollution prevention strategies should be implemented in order to protect the public from exposure to benzene in Taipei. In the short term, the reduction in the proportion of benzene and aromatics in gasoline and the installation of catalysts in motorcycles and cars are two possible ways to cut down benzene emissions from mobile sources in Taipei. In the long run, there are two possible alternatives to solve the benzene problem. One way is to eliminate benzene emissions by phasing in vehicles powered by alternative fuels, such as LPG-fueled or electricity-fueled vehicles. The other way is to shorten commuting duration by building a better public transportation system. We also recommend that indoor air quality survey programs should be carried out in order to identify potential sources of indoor air pollution in offices.

Acknowledgements-We would like to thank the support of the Taiwan Environmental Protection Agency (contract No. EPA-81-E3F1-09-02 and EPA-81-F102-09-03) to fund this study. We would especially like to thank all the volunteers who helped us to carry out the commuting pattern survey and VOC measurements.

\section{REFERENCES}

Bevan M. A. J., Proctor C. J., Baker-Roger J. and Warren N. D. (1991) Exposure to carbon monoxide, respirable suspended particulates, and volatile organic compounds while commuting by bicycle. Envir. Sci. Technol. 25, 788-790.

Chan C. C., Özkaynak H., Spengler J. D. and Sheldon L. (1991) Driver exposure to volatile organic compounds, $\mathrm{CO}$, ozone, and $\mathrm{NO}_{2}$ under different driving conditions. Envir. Sci. Technol. 25, 964-972.

Chan C. C., Spengler J. D., Özkaynak H. and Lefkopoulou M. (1992) Commuter exposure to VOCs in Boston, Massachusetts. J. Air Waste Man. Ass. 41, 1594-1600.

Edgerton S. A., Holdren M. W. and Smith D. L. (1989) Inter-urban comparison of ambient volatile organic compound concentrations in the U.S. cities. J. Air Waste Man. Ass. 39, 729-732.

South Coast Air Quality Management District (SCAQMD, 1989) In-vehicle air toxics characterization study in the south coast air basin: final report. South Coast Air Quality Management District, El Monte, California, October, 1989.

Wallace L. A. (1987) The TEAM study: summary and analysis. EPA 600/6-87/002a. NTIS PB 88-100060; U.S. EPA, Washington, DC, 1987: Vol. I.

Weisel C. P., Lawryk N. J. and Lioy P. J. (1992) Exposure to emissions from gasoline within automobile cabins. J. Expo. Ana. Envir. Epi. 2, 79-96.

Winberry W. T. Jr, Murphy N. T. and Riggin R. M. (1988) Compendium of methods for the determination of toxic organic compounds in ambient air. EPA/600/4-89/017, U.S. EPA, Research Triangle Park, NC, 1988. 